\title{
Absorption, Distribution, Metabolism, and Excretion of Capmatinib (INC280) in Healthy Male Volunteers and In Vitro Aldehyde Oxidase Phenotyping of the Major Metabolite ${ }^{\text {『 }}$
}

\author{
Ulrike Glaenzel, Yi Jin, Regine Hansen, Kirsten Schroer, Gholamreza Rahmanzadeh, Ulrike Pfaar, \\ Jan Jaap van Lier, Hubert Borell, Axel Meissner, Gian Camenisch, and Sylvia Zhao
}

PK-Sciences, Novartis Pharma AG, Basel, Switzerland (U.G., Y.J., G.R., U.P., H.B., A.M., G.C., S.Z.); Preclinical Safety, Novartis Pharma AG, Basel, Switzerland (R.H.); Novartis Global Discovery Chemistry, Novartis Pharma AG, Basel, Switzerland (K.S., A.M.); and PRA Health Sciences, The Netherlands (J.J.v.L.)

Received February 25, 2020; accepted June 24, 2020

\section{ABSTRACT}

Capmatinib (INC280), a highly selective and potent inhibitor of the MET receptor tyrosine kinase, has demonstrated clinically meaningful efficacy and a manageable safety profile in patients with advanced non-small-cell lung cancer harboring MET exon 14-skipping mutations. We investigated the absorption, distribution, metabolism, and excretion of capmatinib in six healthy male volunteers after a single peroral dose of $600 \mathrm{mg}{ }^{14} \mathrm{C}$-labeled capmatinib. The mass balance, blood and plasma radioactivity, and plasma capmatinib concentrations were determined along with metabolite profiles in plasma, urine, and feces. The metabolite structures were elucidated using mass spectrometry and comparing with reference compounds. The parent compound accounted for most of the radioactivity in plasma $(42.9 \% \pm 2.9 \%)$. The extent of oral absorption was estimated to be $49.6 \%$; the $C_{\max }$ of capmatinib in plasma was reached at 2 hours (median time to reach $\mathbf{C}_{\text {max }}$ ). The apparent mean elimination half-life of capmatinib in plasma was 7.84 hours. Apparent distribution volume of capmatinib during the terminal phase was moderate-to-high (geometric mean 473 I). Metabolic reactions involved lactam formation, hydroxylation, $\mathrm{N}$-dealkylation, formation of a carboxylic acid, hydrogenation, $\mathrm{N}$-oxygenation, glucuronidation, and combinations thereof. M16, the most abundant metabolite in plasma, urine, and feces was formed by lactam formation. Absorbed capmatinib was eliminated mainly by metabolism and subsequent biliary/fecal and renal excretion. Excretion of radioactivity was complete after 7 days. CYP phenotyping demonstrated that CYP3A was the major cytochrome P450 enzyme subfamily involved in hepatic microsomal metabolism, and in vitro studies in hepatic cytosol indicated that M16 formation was mainly catalyzed by aldehyde oxidase.

\section{SIGNIFICANCE STATEMENT}

The absorption, distribution, metabolism, and excretion of capmatinib revealed that capmatinib had substantial systemic availability after oral administration. It was also extensively metabolized and largely distributed to the peripheral tissue. Mean elimination half-life was 7.84 hours. The most abundant metabolite, M16, was formed by imidazo-triazinone formation catalyzed by cytosolic aldehyde oxidase. Correlation analysis, specific inhibition, and recombinant enzymes phenotyping demonstrated that CYP3A is the major enzyme subfamily involved in the hepatic microsomal metabolism of $\left[{ }^{14} \mathrm{C}\right]$ capmatinib.

\section{Introduction}

The MET proto-oncogene encodes a receptor tyrosine kinase that plays a role in the activation of signaling pathways involved in cell proliferation, migration, and survival (Sierra and Tsao, 2011; Feng et al., 2014; Smyth et al., 2014; Garajová et al., 2015)). In normal physiologic signaling, the MET pathway is activated by the binding of hepatocyte growth factor (Smyth et al., 2014). Dysregulation of the MET pathway

This study was sponsored by Novartis Pharmaceuticals Corporation. This study was funded by Novartis Pharmaceuticals Corporation.

https://doi.org/10.1124/dmd.119.090324

S This article has supplemental material available at dmd.aspetjournals.org. can occur through several mechanisms and may lead to upregulated cell proliferation, survival, and metastasis (Feng et al., 2014; Garajova et al., 2015; Schrock et al., 2016; Tong et al., 2016). One such mechanism is through genomic mutations, including point mutations or insertions/ deletions, thus leading to exon 14 skipping (Kong-Beltran et al., 2006; Feng et al., 2012; Garajová et al., 2015; Schrock et al., 2016; Salgia, 2017)Kong-Beltran et al., 2006; Feng et al., 2012; Garajova et al., 2015; Schrock et al., 2016; Salgia, 2017). The pathway can also be activated via $M E T$ gene amplification, which occurs in about $1 \%-4 \%$ of newly diagnosed cases with epidermal growth factor receptor-wild-type non-small-cell lung cancer (NSCLC) (Cappuzzo et al., 2009; Kawakami et al., 2014; Schildhaus et al., 2015).

ABBREVIATIONS: ACN, acetonitrile; ADME, absorption, distribution, metabolism, and excretion; AE, adverse event; AO, aldehyde oxidase; AUC, area under the curve; $A \cup C_{\text {inf }}$, area under the plasma analyte concentration-time curve from time 0 to infinity; $A U C_{\text {last }}$ area under the concentration-time curve from 0 to the last measurement; CL/F, apparent plasma clearance; GCN, gene copy number; HLC, human liver cytosol; HLM, human liver microsome; HLS9, human liver S9; HPLC, high-performance liquid chromatography; LC, liquid chromatography; LC-MS/MS, LC-tandem MS; MET ex14, MET exon 14-skipping; MS, mass spectrometry; NSCLC, non-small-cell lung cancer; P450, cytochrome P450; $\mathrm{T}_{\text {max }}$, time to reach $\mathrm{C}_{\max }$; ULN, upper limit of normal; $\mathrm{Vz} / \mathrm{F}$, apparent distribution volume; $\mathrm{XO}$, xanthine oxidase. 
MET exon 14-skipping (METex14) mutations have been reported in $3 \%$ to $4 \%$ of patients with NSCLC (The Cancer Genome Atlas Research Network, 2014; Frampton et al., 2015; Awad et al., 2016; Descarpentries et al., 2018). Patients with METex 14 mutations were found to have worse survival outcomes compared with patients without the MET mutation ((Ludovini et al., 2012; Tong et al., 2016; Vuong et al., 2018).

Capmatinib (INC280) is an orally bioavailable, ATP-competitive, reversible inhibitor of MET with an $\mathrm{IC}_{50}$ of $0.13 \mathrm{nmol} / \mathrm{l}$ as demonstrated in an in vitro MET kinase assay (Liu et al., 2011; Lara et al., 2017). Capmatinib has also been demonstrated to be highly selective compared with other kinases, with more than 1000-fold selectivity among 442 kinases when tested using the KINOMEscan selectivity screening platform (Baltschukat et al., 2019). It is highly potent, as demonstrated in biochemical $\left(\mathrm{IC}_{50} 0.13 \mathrm{nM}\right)$ and cellular $\left(\mathrm{IC}_{50} 0.3-1.1 \mathrm{nM}\right)$ assays across a range of tumor types, including lung, gastric cancer, and glioblastoma, and caused regression of MET-dependent (amplified) tumors in animal models at well-tolerated doses (Liu et al., 2011; Lara et al., 2017). In biochemical and vitro assays, it was found to be 30 times more potent than crizotinib ( $\mathrm{IC}_{50}$ values of 0.13 and $4 \mathrm{nM}$, respectively), (Zou et al., 2007; Liu et al., 2011). In Phase I and II clinical studies, single-agent capmatinib has demonstrated strong activity in patients with NSCLC with a high MET gene copy number (GCN), with an overall response rate of $53 \%$ in patients with $M E T$ GCN $\geq 6$ (Schuler et al., 2018) and 68\% in patients who are treatment-naïve with METex 14 advanced NSCLC (Wolf et al., 2019). In addition, the combination of capmatinib with gefitinib has been shown to be a promising treatment for patients with epidermal growth factor receptor-mutated, METdysregulated NSCLC, particularly for MET-amplified disease, with an overall response rate of $47 \%$ in patients with $M E T$ GCN $\geq 6$ (Wu et al., 2018). Capmatinib is now approved for adult patients with metastatic NSCLC with METex14 mutation.

This single-center, open-label study, conducted as per the International Conference on Harmonization M3 guidelines, investigated the absorption, distribution, metabolism, and excretion (ADME) of capmatinib after a single oral dose of $600 \mathrm{mg}\left[{ }^{14} \mathrm{C}\right]$ capmatinib $(5.55 \mathrm{MBq})$ in healthy male volunteers.

In vitro investigations were conducted to identify the role of aldehyde oxidase (AO), xanthine oxidase (XO), and CYP P450 enzymes in the metabolism of capmatinib. The study results provide data to characterize the main elimination pathways.

\section{Materials and Methods}

\section{Study Drug}

Radiolabeled $\left[{ }^{14} \mathrm{C}\right]$ capmatinib was prepared by Novartis Isotope Laboratory of Novartis, Basel, Switzerland. Capmatinib was labeled with ${ }^{14} \mathrm{C}$ in a metabolically stable position, as shown in Fig. 1.

The radiolabeled study drug was provided as individually packaged doses of $\left.12 \times 50 \mathrm{mg} \mathrm{[}{ }^{14} \mathrm{C}\right]$ capmatinib-free base in hard gelatin capsules with a nominal specific activity of $9.25 \mathrm{kBq} / \mathrm{mg}$ (total dose of $5.55 \mathrm{MBq}$ ). The 12 hand-weighed capsules per bottle corresponded to a nominal dose of $600 \mathrm{mg}$ of capmatinib. The analyses of chemical and radiochemical identity, purity, and stability were performed according to predefined and quality assurance-approved specifications, and the drug was released for human use.

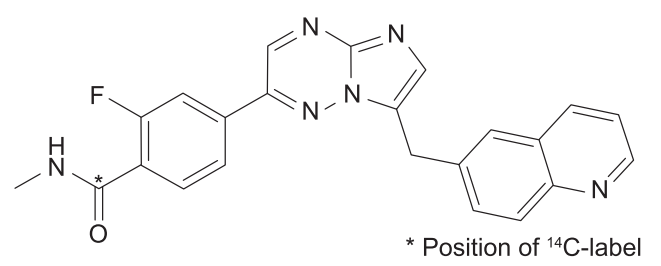

Fig. 1. Structure of radiolabeled capmatinib (INC280).
The actual specific radioactivity of the solid drug substance, measured at Novartis Isotope Laboratory, was $9.185 \mathrm{kBq} / \mathrm{mg}$. The deviation between the actual specific radioactivity and nominal specific radioactivity was $0.7 \%$. The actual specific radioactivity was used for all further calculations. The radiochemical purity of the radiolabeled drug product was $99.7 \%$, with individual impurities accounting for $\leq 0.2 \%$. Hence, no impurity is expected to confound the metabolite investigations.

\section{Chemicals and Standards}

Unlabeled capmatinib, $\left[{ }^{14} \mathrm{C}\right]$ capmatinib, $\left[{ }^{13} \mathrm{CD}_{3}\right]$ capmatinib (internal standard), and reference standards for the metabolites M3, M8, M13, M16 (CMN288), M17, M18, M19, and M21 were synthesized by Novartis. Other chemicals and solvents were obtained from commercial sources and were of analytical grade.

\section{Study Design}

This open-label, single-center, ADME study of a single oral dose of $600 \mathrm{mg}$ $\left[{ }^{14} \mathrm{C}\right]$ capmatinib enrolled six healthy male volunteers, with the objective of having at least four volunteers completing the study. The study consisted of the following periods:

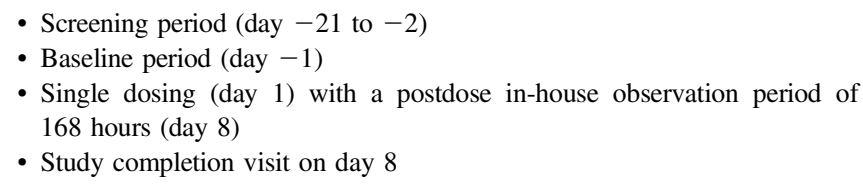

Volunteers who met the inclusion criteria and were confirmed to be eligible according to predose safety evaluations received a single oral dose of $\left[{ }^{14} \mathrm{C}\right]$ capmatinib. Key inclusion criteria included male volunteers, 45-65 years of age and in good health, as determined by past medical history, physical examination, ECG, and laboratory tests at screening; normal vital signs at screening and baseline (temperature, systolic and diastolic blood pressure, and pulse rate); weight between 50 and $90 \mathrm{~kg}$ with a body mass index of $18-29 \mathrm{~kg} / \mathrm{m}^{2}$; and laboratory values within the normal range [including blood counts, electrolytes, and blood lipids; total bilirubin $\leq$ upper limit of normal (ULN); alanine aminotransferase and aspartate aminotransferase $\leq$ ULN; gamma-glutamyl transferase $\leq 1.5 \mathrm{ULN}$; alkaline phosphatase $\leq \mathrm{ULN}$; serum creatinine $\leq \mathrm{ULN}$; serum amylase and lipase $\leq$ ULN; Hb levels within normal limits; abnormal urinary constituents $\leq$ ULN].

Key exclusion criteria included a history of hypersensitivity to the study drug or to drugs of similar chemical classes or excipients, past medical history of or current clinically significant ECG abnormalities/arrhythmias or a family history of a prolonged QT-interval syndrome, relevant radiation exposure $(>0.2$ millisieverts) within 12 months prior to scheduled dosing with $\left[{ }^{14} \mathrm{C}\right]$ capmatinib, smokers (use of tobacco products in the previous 3 months), and any surgical or medical condition that could significantly alter the ADME of drugs (e.g., history of inflammatory bowel syndrome, ulcers, gastrointestinal or rectal bleeding, gastritis, or major gastrointestinal surgery).

The primary objectives of the study were to determine the pharmacokinetics of total radioactivity in blood and plasma, to determine the rates and routes of excretion of $\left[{ }^{14} \mathrm{C}\right]$ capmatinib-related radioactivity (including mass balance of total drug-related radioactivity in urine and feces), and to characterize the plasma pharmacokinetics of capmatinib. The secondary objective was to assess the safety and tolerability of a single $600 \mathrm{mg}$ oral dose of $\left[{ }^{14} \mathrm{C}\right]$ capmatinib administered to healthy male volunteers. Exploratory objectives included identification and (semi) quantification of the metabolites of capmatinib in plasma, urine, and feces to elucidate the key biotransformation pathways and clearance mechanisms of capmatinib in humans, and characterization of plasma exposure and pharmacokinetics of metabolites based on radiometry data. This study was performed in accordance with the ethical principles of the Declaration of Helsinki and the principles of Good Clinical Practice. The protocol was approved by an Institutional Review Board at each hospital or site, and all volunteers provided written informed consent before any study procedures were performed.

\section{Drug Administration}

On day 1 , after a fasting period of at least 10 hours, volunteers received a single, oral, nominal dose of $600 \mathrm{mg}(5.55 \mathrm{MBq}$ or $150 \mu \mathrm{Ci})\left[{ }^{14} \mathrm{C}\right]$ capmatinib-free base 
in 12 capsules of $50 \mathrm{mg}$ each, which were taken consecutively together with one glass of noncarbonated water $(\sim 240-480 \mathrm{ml})$. The dose was based on the recommended phase 2 dose for single-agent capmatinib determined in clinical studies (Ma et al., 2015). The expected radiation exposure was estimated according to the recommendations of the International Commission on Radiologic Protection.

\section{Sample Collection and Aliquoting}

Blood and Plasma Samples. A total of 16 blood samples were collected at the time points of $0^{*}$ (predose day 1 ), $0.5^{*}, 1,2^{*}, 3^{*}, 4,6^{*}, 8,12^{*}, 24,48^{*}, 72,96$, $120^{*}, 144$, and $168^{*}$ hours postdose. A blood volume of $24 \mathrm{ml}$ was collected at specified time points (*) and $10 \mathrm{ml}$ at all other time points. All blood samples were taken by either direct venipuncture or an indwelling cannula inserted in a forearm vein into $\mathrm{K}_{2}$-EDTA (pharmacokinetics) or $\mathrm{K}_{3}$-EDTA (hematology) tubes. Three aliquots of $0.3 \mathrm{ml}$ were removed from each sample for radioactivity determination.

The remaining blood was then centrifuged at $4^{\circ} \mathrm{C}$ to obtain plasma. From the total plasma, three weighed aliquots of $0.25 \mathrm{ml}$ each were removed for radioactivity determination, and two aliquots of $0.5 \mathrm{ml}$ was reserved for the analysis of capmatinib. The remaining plasma was then used for metabolite analysis.

After aliquoting for the different assays, the blood and plasma samples were immediately frozen and stored at $<-60^{\circ} \mathrm{C}$ until analysis.

Urine and Fecal Samples. For each volunteer, a predose (blank) urine sample was collected on day -1 . After administration of the radiolabeled dose, all urine was collected for the time intervals of $0-6,6-12$, and 12-24 hours and thereafter in 24-hour fractions up to 168 hours. Aliquot(s) were separated for radioactivity determination. The urine samples were frozen and stored at $<-60{ }^{\circ} \mathrm{C}$ until analysis.

For each volunteer, a predose (blank) fecal sample was also collected on day -1 . After the radiolabeled dose on day 1 , all fecal samples were collected during the postdose sample collection period of 168 hours. The fecal samples were quantitatively transferred into a container for each volunteer per 24-hour interval. A minimum amount (one to two weight equivalents) of water-containing carboxymethyl cellulose (Sigma Aldrich, NL) was added. The total amount of carboxymethyl cellulose (by weight) did not exceed $1.5 \%$. The samples were thoroughly homogenized for at least 10 minutes using an Ultra Turrax mixer. After homogenization, aliquot(s) were separated for radioactivity determination. All remaining homogenate samples were stored at $-20^{\circ} \mathrm{C}$.

The radiometry samples were analyzed at the Bioanalytical Laboratories of PRA International - Early Development Services, Assen, The Netherlands. Metabolism samples were analyzed at Novartis Institutes for BioMedical Research, Novartis.

\section{Pharmacokinetic Evaluations}

Pharmacokinetic parameters were calculated using WinNonlin software version 6.3 for nonradiolabeled assays and version 6.3 or 6.4 for radiolabeled assays (Pharsight, Mountain View, CA) using noncompartmental methods. The fraction of radioactivity associated with the plasma (Fp) was calculated from blood $(\mathrm{Cb})$ and plasma $(\mathrm{Cp})$ concentrations of radioactivity and from the hematocrit value $(\mathrm{H})$ as follows: $\mathrm{Fp}(\%)=(\mathrm{Cp} / \mathrm{Cb}) \times(1-\mathrm{H}) \times 100$.

\section{Total Radioactivity Measurement}

Radioactivity in blood, plasma, urine, and feces was measured using liquid scintillation counting with typical counting times of 10 or 30 minutes. Detailed summary of the procedure used for detection of radioactivity is included in the Supplemental Materials.

\section{Determination of Capmatinib Concentrations in Plasma}

Concentration of unchanged capmatinib in plasma was measured by a validated liquid chromatography-tandem mass spectrometry (LC-MS/MS) assay. The detailed procedure used for the determination of capmatinib concentration in plasma is described in the Supplemental Materials.

\section{Determination of Metabolite Profiles in Plasma and Excreta}

For metabolite profiling in plasma, the individual samples of volunteers taken at $0.5,1,2,3,6$, and 12 hours after the $\left[{ }^{14} \mathrm{C}\right]$ capmatinib dose were analyzed. Each plasma sample was extracted three times with mixtures of ACN, methanol, and/or water. The final extracts were evaporated, reconstituted in mixtures of $\mathrm{ACN}$ and water, and analyzed using high-performance liquid chromatography (HPLC). The total recovery of the radioactivity in the plasma samples after extraction, reconstitution, and HPLC yielded in average 94.1\% (range 92.5\%-97.5\%) of the total radioactivity area under the curve (AUC) from 0 to 12 hours.

Urine samples from each volunteer were pooled across the collection period of 0-96 hours. On average, the six pools represented $99.3 \%$ of the radioactivity excreted with urine. After centrifugation, a volume of $250 \mu \mathrm{l}$ from each urine pool was injected into the HPLC-MS system with offline radioactivity detection. The recovery of the radioactivity after centrifugation and HPLC analysis was found to be complete $(100.0 \%)$.

Feces samples from each volunteer were pooled across the collection period of 0-96 hours. On average, the six pools represented $97.9 \%$ of the radioactivity excreted with feces. Aliquots of the feces homogenate $(\sim 5 \mathrm{~g})$ were extracted four times with ACN, methanol, aqueous ACN acidified with formic acid, and acetone by sonication and centrifugation. The combined extracts were evaporated and reconstituted in mixtures of $\mathrm{ACN}$ and water for further analysis. The extractions yielded between $91.7 \%$ and $98.5 \%$ (mean $95.1 \%$ ) of radioactivity.

The stability of capmatinib and its metabolites in the biologic samples was demonstrated by repeated extractions and analyses during the study. The stability of capmatinib during sample preparation and HPLC analysis was investigated using blank plasma, urine, and feces spiked with $\left[{ }^{14} \mathrm{C}\right]$ capmatinib. No degradations were observed.

\section{HPLC Instrumentation for Metabolite Pattern Analysis}

The chromatography was performed on an Agilent 1100 (Agilent Technologies, Waldbronn, Germany) HPLC system, equipped with a binary capillary pump, a column oven, a degasser, and a UV-visible spectroscopy diode array detector with a standard 13- $\mu$ l flow cell. The operating software for the HPLC system was Agilent ChemStation for LC 3D, Rev. B.04.02 SP1 [208]. Volumes up to $250 \mu$ l were injected into a 350- $\mu$ l sample loop using HTS PAL autosampler (CTC, Zwingen, Switzerland). The components were separated at $40^{\circ} \mathrm{C}$ on an ACE C18 analytical column $(150 \times 4.6 \mathrm{~mm}, 3 \mu \mathrm{m}$; Advanced Chromatography Technologies, Aberdeen, Scotland, UK) protected by a $20 \times 2.1-\mathrm{mm}$ guard column of the same stationary phase.

The mobile phase consisted of ammonium formate $10 \mathrm{mM}(\mathrm{pH} 2.76)(\mathrm{A})$ and ACN (B). The flow rate was $900 \mu \mathrm{l} / \mathrm{min}$. The gradient used was: $0-5$ minutes, $5 \%$ B isocratic; 5-20 minutes, 5\%-12\% B linear gradient; 20-55 minutes, 12\%-20\% B linear gradient; 55-65 minutes, 20\%-50\% B linear gradient; 65-65.1 minutes, $50 \%-100 \%$ B linear gradient; and $65.1-70$ minutes, $100 \%$ B isocratic.

For hydrogen/deuterium exchange experiments, the water in the mobile phase A was replaced by deuterium oxide. For improved separation of the metabolites M8 and M28, the mobile phase A was replaced by ammonium formate $20 \mathrm{mM}, \mathrm{pH} 5.50$.

\section{Structural Characterization of Metabolites}

Structural information on the metabolites was obtained by LC-MS/MS analysis using electrospray ionization in the positive-ion mode and comparison with the available authentic reference standards M3, M8, M13, M16, M17, M18, M19, and M21 (refer to Supplemental Materials). Parallel radioactivity detection was used for peak correlation with mass spectral data. After chromatography, the effluent was split into a ratio of approximately 1:8. The smaller portion was directed into the electrospray LC-MS interface. The larger portion was used for UV detection followed by offline radioactivity detection.

Single-stage or product-ion spectra with exact mass determination were obtained on a time-of-flight mass spectrometer (Synapt G2-S; Waters Corporation, Manchester, UK) in positive-ion mode.

Structure assignment was achieved based on molecular ions $\left(\mathrm{M}+\mathrm{H}^{+}\right)$, exact mass measurements, hydrogen/deuterium exchange experiments, and several key fragment characteristic for specific moieties of the molecule; comparison of HPLC or LC-MS data with synthetic reference compounds; or comparison with metabolites from previous metabolism studies. NMR spectroscopy data are provided in the Supplemental Materials.

\section{In Vitro Experiments}

The metabolite profiles of capmatinib in liver fractions (homogenate, S9, microsomes, and cytosol) were studied in the absence and presence of NADPH 
To determine the enzymes involved in the catalysis of the formation of major hepatic metabolites, enzyme-phenotyping studies were carried out using CYP and $\mathrm{AO} / \mathrm{XO}$ enzymes.

CYP phenotyping was carried out to investigate the human enzymes involved in the oxidative metabolism of capmatinib in human liver microsomes (HLMs) using selective chemical inhibitors, recombinant enzyme kinetics, and correlation analysis with a panel of 16 single donors human liver microsomes. In addition, phenotyping was performed with recombinant $\mathrm{AO}$ and $\mathrm{XO}$ to investigate the formation of metabolites M16 and M19 in human liver cytosol (HLC). Additionally, a mechanistic experiment was performed using ${ }^{18} \mathrm{O}$ water to investigate the contribution of $\mathrm{AO} / \mathrm{XO}$ in the biotransformation of capmatinib for the metabolites M4, M5, M8, M16, and M19. Detailed methods for the in vitro experiments are included in the Supplemental Materials.

\section{Assessment of Safety}

Safety assessments included collection of all adverse events (AEs), serious AEs, eye exams, pregnancies (if female partners of any male volunteer who took the study drug became pregnant within 3 months after dose administration) and monitoring of vital signs, laboratory evaluations, and ECGs.

\section{Results}

\section{Disposition of Volunteers}

Of the 18 volunteers screened, six were treated in the study. The primary reasons for screening failures were unacceptable test results and not meeting the diagnostic or inclusion criteria. The six volunteers were male and Caucasian, with a median age of 52.0 years (range 46-58 years) and a median body mass index of $25.87 \mathrm{~kg} / \mathrm{m}^{2}$ (range $24.91-26.50 \mathrm{~kg} / \mathrm{m}^{2}$ ).

\section{Concentrations of Radioactivity and Capmatinib in Plasma/Blood}

After oral dosing of $600 \mathrm{mg}\left[{ }^{14} \mathrm{C}\right]$ capmatinib capsules, the extent of oral absorption was estimated to be $49.6 \% \pm 20.9 \%$ (range $21.0 \%-81.7 \%$ ) based on excretion of metabolites in urine and feces (Supplemental Table 2). Radioactivity in plasma was detected for up to 48 hours, and unchanged capmatinib was detected in plasma for up to 72 hours postdose. The $\mathrm{C}_{\max }$ of radioactivity and capmatinib in plasma was reached at 2 hours ( $\mathrm{T}_{\max }$, median values) (Fig. 2; Table 1). The apparent distribution volume $(\mathrm{Vz} / \mathrm{F})$ of capmatinib during the terminal phase was moderate-to-high (geometric mean: 473 1). The apparent plasma clearance (CL/F) of capmatinib was moderate-to-high (geometric mean: $45.5 \mathrm{l} / \mathrm{h}$ ). The apparent mean terminal half-lives of total radiolabeled components and capmatinib in plasma were 10.6 and 7.84 hours, respectively.

The interindividual variability in systemic exposure [area under the plasma analyte concentration-time curve from time 0 to infinity $\left.\left(\mathrm{AUC}_{\mathrm{inf}}\right)\right]$ to total radiolabeled components and capmatinib was moderate. The $\mathrm{CV}$ for $\mathrm{C}_{\max }$ was $48.9 \%$ for total radiolabeled components and $46.7 \%$ for capmatinib. The $\mathrm{CV}$ for $\mathrm{AUC}_{\mathrm{inf}}$ was $34.9 \%$ for total radiolabeled components and $36.9 \%$ for capmatinib. The shape of the concentration-time curves for radioactivity and capmatinib was comparable in individual volunteers. About $31.5 \%$ of plasma radioactivity was due to capmatinib in the period 0 to infinity $\left(33.0 \%\right.$ of the $\left.{ }^{14} \mathrm{C}-\mathrm{AUC}_{\text {last }}\right)$, indicating substantial exposure to metabolites. In blood, radioactivity was detected for up to 48 hours postdose, after which radioactivity levels were near or below limit of quantification. The mean blood/plasma AUC ratio of radioactivity was 1.14 (range 0.96-1.43), indicating that capmatinib-related components were slightly more confined within the blood than the plasma compartment. These data are in line with the in vitro capmatinib blood-to-plasma ratios, which were close to unity with ratios of $0.9-1.4$.

\section{Excretion and Mass Balance of Radioactivity in Urine and Feces}

Excretion of radioactivity was complete after 7 days (mean, 99.7\%; range $94.8 \%-104 \%$ ). Figure 3 depicts the cumulative excretion of radioactivity in urine and feces. A major proportion of radioactivity (97.9\%) was excreted within 4 days. Unchanged capmatinib amounted to $42.1 \% \pm 23.0 \%$ of the dose and ranged between $9.3 \%$ and $72.64 \%$. Differences in the dissolution of the twelve capsules might be a possible explanation for the large differences between individuals. A large proportion of the administered radioactivity was excreted within the feces and amounted to $77.9 \% \pm 10.3 \%$ of the dose (range $66.59-92.72$ ). Only $21.8 \% \pm 8.5 \%$ of the administered radioactivity was excreted in urine (range 8.88-31.51).

\section{Metabolite Profiles in Plasma, Urine, and Feces}

Metabolite profiles in plasma for each volunteer were analyzed by HPLC, with radioactivity detection at 0.5-, 1-, 2-, 3-, 6-, and 12-hour time points. No major relative difference was observed between volunteers in the plasma metabolite profiles. Overall, more than $90 \%$ of detected radioactive components of the plasma $\mathrm{AUC}_{0-12 \mathrm{~h}}$ and extrapolated $\mathrm{AUC}_{\mathrm{inf}}$ could be covered by the parent drug and structurally characterized metabolites. The parent compound capmatinib contributed to a large proportion of radioactivity in plasma $\left(42.9 \% \pm 2.9 \%\right.$ of the plasma $\mathrm{AUC}_{0-12 \mathrm{~h}}$ ). Metabolite M16 (formed by imidazo-triazinone formation) was the most prominent metabolite in plasma and amounted to $21.5 \% \pm 2.1 \%$ of the plasma $\mathrm{AUC}_{0-12 \mathrm{~h}}$ (Table 2). Minor proportions of other metabolite peaks were detected and were attributed to the metabolites M8 and M28, with each accounting on average for $5.4 \%-5.9 \%$ of the plasma $\mathrm{AUC}_{0-12}$ h. The metabolites M8 and M28 were formed by hydroxylation of the methylene group and N-dealkylation/hydroxylation (or lactam formation), respectively. The metabolites M18, $\mathrm{M} 26$, and M13 amounted to less than 3.0\% of the plasma $\mathrm{AUC}_{0-12 \mathrm{~h}}$ each. The metabolites were formed by $\mathrm{N}$-dealkylation, hydrogenation, and carboxylic acid formation, respectively. Supplemental Table 1 provides the plasma $\mathrm{AUC}_{0-12} \mathrm{~h}$ for capmatinib and its metabolites. Numerous other metabolites (in total 15) individually contributed to less than $2 \%$ of the plasma $\mathrm{AUC}_{0-12 \mathrm{~h}}$. The metabolites were formed by hydroxylation/lactam formation, hydrolysis of the amide bond, N-dealkylation, N-oxygenation, oxygenation, hydrogenation, and/or glucuronidation.

Unchanged capmatinib in urine was only detected in traces, indicating extensive metabolism of the systemically available capmatinib. The most abundant plasma metabolite M16 (imidazo-triazinone formation) was also found in urine and accounted for $2.9 \% \pm 1.2 \%$ of the dose. In addition, numerous other minor metabolites were detected (Supplemental Table 2), with each being less than $2.0 \%$ of the dose. No major relative difference was observed between volunteers in the urinary metabolite profiles. More than $19.2 \%$ of dose $(89 \%$ of total radioactivity in the 0-96-hour urine pool) could be covered by capmatinib and structurally characterized metabolites.

The most abundant metabolite in feces of healthy volunteers was M16 $(5.1 \% \pm 2.1 \%)$. Two additional metabolites accounted for more than $2 \%$ of the radioactivity dose in feces (i.e., the hydrogenated metabolite M26 amounted for $3.3 \% \pm 1.1 \%$ and the oxygenated metabolite M20 amounted for $2.3 \% \pm 1.1 \%$ ). Fifteen other metabolites were identified, with each metabolite contributing less than $2 \%$ of the dose each in feces (Supplemental Table 2). The primary AO/ XO metabolites M16 and M19 represented $20.8 \%$ of all metabolites in excreta. The metabolite profiles in feces were comparable, but large differences were found for capmatinib. Representative metabolite profiles in plasma ( 2 and 12 hours), urine, and feces are depicted in 


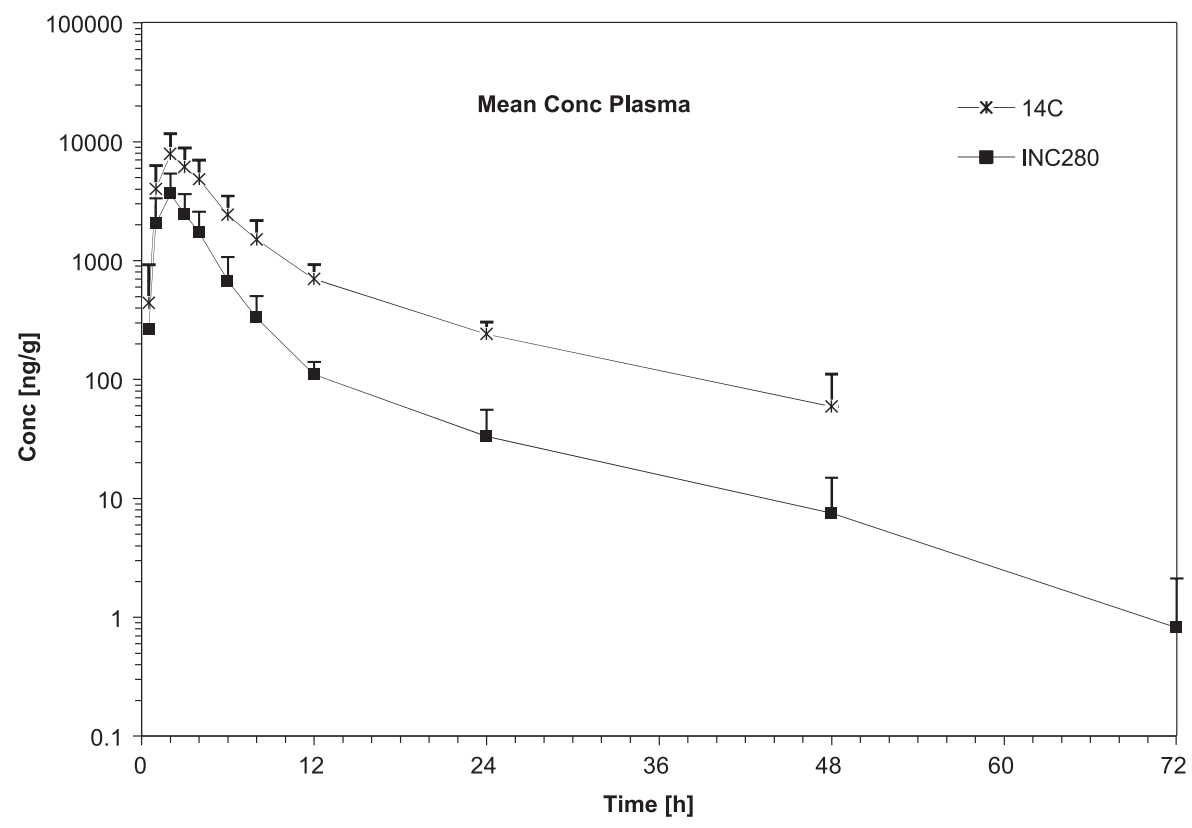

Fig. 2. Mean plasma concentrations $(N=6$, \pm S.D. $)$ of radioactivity and capmatinib (semilogarithmic scale).

Fig. 4. The metabolites were mainly formed by hydroxylation/lactam formation, hydrolysis of the amide bond, N-dealkylation, and/or hydrogenation. Metabolites formed by glucuronidation and $\mathrm{N}$-oxygenation were not detected. More than $65.9 \%$ of the dose $(86.4 \%$ of total radioactivity in the $0-96$-hour feces pool) could be covered by capmatinib and structurally characterized metabolites.

Supplemental Fig. 1 depicts the plasma metabolite profile observed in rats after single oral administration of $\left[{ }^{14} \mathrm{C}\right]$ capmatinib in a rat ADME study. Exposure coverage of metabolite M16 by the toxicology species rat was assessed by comparison of metabolite exposure in humans with the metabolite exposures in the rat ADME study. Adequate exposure of the major human plasma metabolite M16 was obtained in toxicological evaluations of rat and also monkey according to the International Conference on Harmonization M3 (R2) guidance. The metabolite M16 was tested in biochemical and cellular assays to determine its pharmacological activity in comparison with capmatinib but showed no measurable activity (Novartis data on file).

Data from LC-MS/MS runs of plasma, urine, and feces extracts are summarized in Supplemental Tables 3A and 3B. Figure 5 depicts the electrospray mass spectrum of capmatinib. The proposed biotransformation pathways and schematic overview are depicted in Fig. 6.

\section{In Vitro Enzyme Phenotyping}

Key results from the in vitro experiments are described below. Detailed results are included in the Supplemental Materials.

Metabolite Profiles in Liver Fractions. Figure 7 depicts the metabolite patterns of capmatinib in human hepatocytes and three hepatic subcellular fractions [HLM, HLC, human liver S9 fraction (HLS9)]. In HLM, high metabolic activity of capmatinib was observed in the presence of NADPH with M8 as the major metabolite and M4, M5, M17, and M21 as the four minor metabolites. Formation of M8 and the four minor metabolites was increased in the presence of NADPH, indicating involvement of CYP450 enzymes. HLM was used to investigate the microsomal contribution of CYP P450 enzymes.

In the hepatic cytosol fraction incubations, M16 (imidazo-triazinone or lactam metabolite) and M19 (quinolinone metabolite) were the two main metabolites observed in HLC. The concentration-dependent

TABLE 1

Primary pharmacokinetic parameters of radioactivity and capmatinib in blood and plasma (based on noncompartmental analysis)

Values are shown as mean ${ }^{\mathrm{a}}$ (S.D.) for $\mathrm{N}=6$ volunteers unless mentioned otherwise.

\begin{tabular}{|c|c|c|c|}
\hline PK Parameter & Blood Radioactivity & Plasma Radioactivity & Plasma Capmatinib \\
\hline $\mathrm{T}_{\max }[\mathrm{h}]$ (median; range) & $2 ; 1$ to 2 & $2 ; 1$ to 2 & $2 ; 1$ to 2 \\
\hline $\mathrm{C}_{\max }[\mathrm{ng} / \mathrm{ml}]^{b}$ & $7300(2880)$ & $7850(3840)$ & $3670(1710)$ \\
\hline $\mathrm{T}_{\text {last }}[\mathrm{h}]$ (range) & $24-48$ & $24-48$ & $24-72$ \\
\hline $\mathrm{AUC}_{\text {last }}[\mathrm{ng} \cdot \mathrm{h} / \mathrm{ml}]^{c, d}$ & $47,400(13,700)$ & $43,800(16,400)$ & $14,300(5330)$ \\
\hline$t_{1 / 2}[\mathrm{~h}]$ & $8.5(4.8)$ & $10.6(4.0)$ & $7.8(3.1)$ \\
\hline \multirow[t]{2}{*}{$\mathrm{AUC}_{\mathrm{inf}}^{e}[\mathrm{ng} \cdot \mathrm{h} / \mathrm{ml}]^{c, d}\left[\%\right.$ of ${ }^{14} \mathrm{C}-\mathrm{AUC}_{\mathrm{inf}}$ plasma $]$} & $49,700(13,400)$ & $45,500(15,900)$ & $14,400(5310)$ \\
\hline & $114.3(17.6)$ & - & $31.5(2.9)$ \\
\hline AUC $\%$ Extrap $\left[\%\right.$ of $\left.\mathrm{AUC}_{\mathrm{inf}}\right]$ & $5.3(3.9)$ & $5.0(4.5)$ & $0.5(0.6)$ \\
\hline $\mathrm{Vz} / \mathrm{F}[1]$ & - & - & $624(511)$ \\
\hline $\mathrm{CL} / \mathrm{F}[\mathrm{l} / \mathrm{h}]$ & - & - & $51.7(34.4)$ \\
\hline
\end{tabular}

NA, not applicable; PK, pharmacokinetic; $\mathrm{T}_{\text {last }}$, time point corresponding to the last measurable concentration; $t_{1 / 2}$, half-life; -, not calculable/not meaningful.

${ }^{a}$ Mean values are arithmetic means of individual values.

${ }^{b}$ For radioactivity: [ng-eqper $\mathrm{ml}$ ].

${ }^{c}$ For radioactivity: [ng-eq.h per $\mathrm{ml}$ ].

${ }^{d} \mathrm{AUC}_{\mathrm{last}}$ were calculated using the linear trapezoidal rule. The typical time interval was 8-24 h for blood radioactivity and $12-48 \mathrm{~h}$ for plasma radioactivity and plasma capmatinib.

${ }^{e} \mathrm{AUC}_{\mathrm{inf}}=\mathrm{AUC}_{\text {last }}+\mathrm{AUC}_{\mathrm{t} \text {-inf }} ; \mathrm{AUC}_{\mathrm{t} \text {-inf }}=\mathrm{C}_{\text {last }} * t_{1 / 2} / \mathrm{ln} 2$. Eq, equivalent; Extrap, extrapolated; $\mathrm{AUC}_{\mathrm{t} \text {-inf }} ;$ AUC from t $\mathrm{t}_{\text {last }}$ to infinity. 


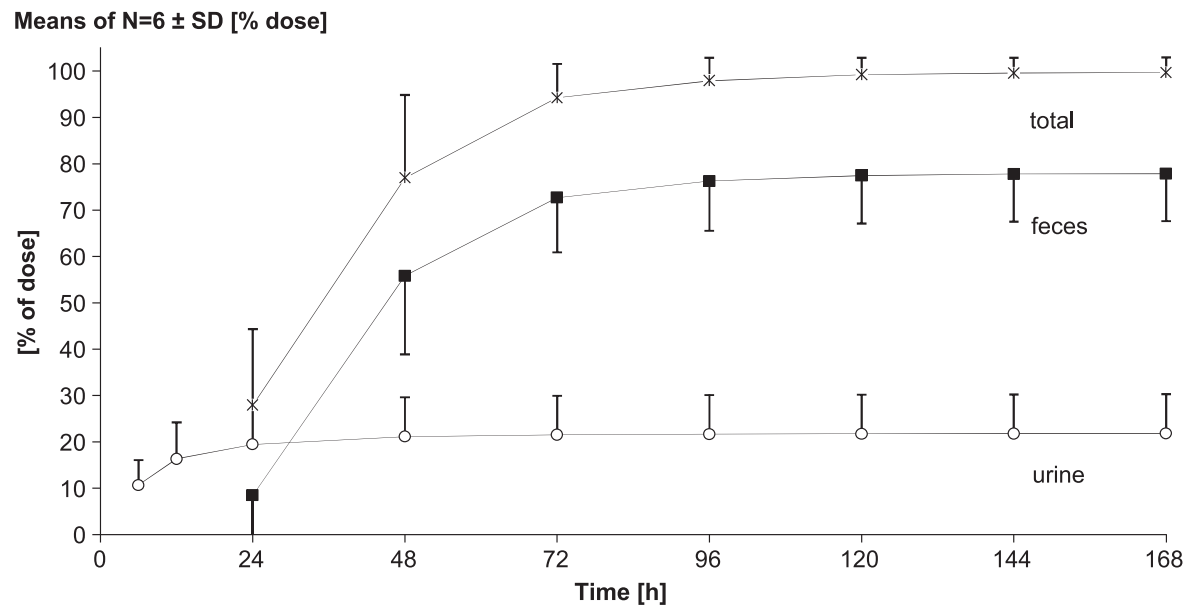

Fig. 3. Cumulative excretion of radioactivity in urine and feces.

biotransformation of $\left[{ }^{14} \mathrm{C}\right]$ capmatinib by human liver cytosol $(0.4 \mathrm{mg}$ protein $/ \mathrm{ml}$ ) was investigated after 120-minute incubation time. Individual and mean values for two incubations are provided in Supplemental Tables 4A and 4B. In the incubation with HLS9 without NADPH, the oxidative metabolites M16 and M19 were detected with M8, which might be because of the presence of trace amounts of native NADPH in the S9 preparation (Fig. 8). The catalysis of metabolites M16 and M19 does not require NADPH as an enzyme cofactor. The metabolite patterns in HLS9 with NADPH were qualitatively comparable with the pattern obtained in human hepatocytes. The metabolites formed in HLM (M8 and minor ones) and in the HLC (M16 and M19) were both found in HLS9.

AO Phenotyping and XO Involvement in the Metabolic Formation of M16 and M19. The apparent $K_{m}$ values for biotransformation to metabolite M16 and M19 in HLC were 8.84 and $18.5 \mu \mathrm{M}$, respectively; $\mathrm{V}_{\max }$ was 21.5 and $11.2 \mathrm{pmol} / \mathrm{min}$ per milligram, respectively. The derived intrinsic clearances were low (2.43 and $0.605 \mu 1 / \mathrm{mg}$ per minute for M16 and M19 formation, respectively). The enzyme kinetic parameters for the formation of M16 and M19 by AO, XO, and HLC estimated by simulation assuming Michaelis-Menten type behavior are provided in Supplemental Table 5.

Among the six recombinant or purified molybdenum hydroxylases investigated, a significant amount of M16 and M19 was found with recombinant AO expressed in Escherichia coli cells, whereas XO was able to catalyze the production of M19 (Fig. 9; Supplemental Tables 6A and 6B). Allopurinol (XO inhibitor) showed lower or partial inhibition for the formation of M16 and M19, whereas all four AO inhibitors (raloxifene, menadione, isovanillin, and hydralazine) investigated showed strong or total inhibition in HLC (Fig. 10; Supplemental Fig. 2). Incubations of $\left[{ }^{14} \mathrm{C}\right]$ capmatinib with human hepatocytes in the presence of ${ }^{18} \mathrm{O}$-water showed a major incorporation of ${ }^{18} \mathrm{O}$ for the formation of metabolites M16 and M19 but not for M4, M5, and M8, indicating oxidation by a molybdenumcontaining hydroxylase for the metabolites M16 and M19 (Supplemental Figs. 3 and 4). The results for metabolites M2, M3, M16, M19, M28, M10, M14, M20, and M49 indicated oxidation by molybdenum-containing hydroxylases partly in combination with other metabolic reactions. In total, these metabolites represented $39.7 \% \pm 2.2 \%$ of the metabolites in the excreta of human

TABLE 2

$\mathrm{AUC}_{0-12 \mathrm{~h}}$ of capmatinib and its metabolites in plasma

The $\mathrm{AUC}_{0-12 \mathrm{~h}}$ of capmatinib and its major metabolites was determined in plasma.

\begin{tabular}{|c|c|c|c|c|c|}
\hline \multirow{3}{*}{$\operatorname{Peak}^{a}$} & \multirow{3}{*}{ Compound/Metabolite } & \multicolumn{4}{|c|}{$\mathrm{AUC}_{0-12 \mathrm{~h}}$} \\
\hline & & \multicolumn{4}{|c|}{ Mean \pm S.D., $N=6^{b, c}$} \\
\hline & & \multicolumn{2}{|c|}{$(\mu \mathrm{mol} \cdot \mathrm{h} / \mathrm{l})$} & \multicolumn{2}{|c|}{$\left(\%\right.$ of total $\left.{ }^{14} \mathrm{C}\right)$} \\
\hline M28 & C-hydroxylation ${ }^{d}$ and N-dealkylation & 5.40 & \pm 3.14 & 5.9 & \pm 1.6 \\
\hline M8 (CMN290) & C-hydroxylation of methylene group & 5.06 & \pm 2.51 & 5.4 & \pm 1.6 \\
\hline M26 & Hydrogenation & 1.87 & \pm 0.658 & 2.2 & \pm 0.5 \\
\hline $\operatorname{M16}(\mathrm{CMN} 288)^{e}$ & Imidazo-triazinone formation & 18.9 & \pm 7.89 & 21.5 & \pm 2.1 \\
\hline M18 (CNJ294) & N-dealkylation & 2.81 & \pm 1.70 & 2.9 & \pm 1.0 \\
\hline M13 (CMC583) & Formation of carboxylic acid & 1.56 & \pm 0.555 & 2.2 & \pm 1.6 \\
\hline \multirow[t]{4}{*}{ Capmatinib } & Parent drug & 38.3 & \pm 16.4 & 42.9 & \pm 2.9 \\
\hline & Sum of minor identified metabolite (each less than $2 \%)^{f}$ & 8.02 & \pm 3.59 & 8.9 & \pm 0.9 \\
\hline & Sum of unknown trace metabolites & 1.31 & \pm 0.531 & 2.2 & \pm 2.6 \\
\hline & Lost during sample processing and HPLC & 4.80 & \pm 2.19 & 5.9 & \pm 1.9 \\
\hline \multicolumn{2}{|c|}{ Total ${ }^{14} \mathrm{C}$ (total of radiolabeled components) } & 88.0 & \pm 36.2 & 100 & - \\
\hline
\end{tabular}

-, not meaningful.

${ }^{a}$ Listed according to appearance in chromatogram

${ }^{b}$ Mean values of $N=6$ volunteers.

${ }^{c}$ Mean values are means of individual values.

${ }^{d}$ Hydroxylation on a carbon atom or further isomerization to lactam moiety.

${ }^{e}$ Mean $\mathrm{AUC}_{\text {inf }}$ was assessed and amounted to $20.3 \pm 7.50 \mu \mathrm{mol} \cdot \mathrm{h} / \mathrm{l}\left(21.2 \% \pm 2.2 \%\right.$ of total $\left.{ }^{14} \mathrm{C}\right)$.

${ }^{f}$ Details available in Supplemental Table 1. 
A Representative plasma metabolite profile at $2 \mathrm{~h}$ (Tmax) and $12 \mathrm{~h}$ obtained by HPLC after direct injection of a plasma extract and subsequent detection of radioactivity in 96 -well plates (Topcount ${ }^{\circledR}$ technique).

Plasma, $2 \mathrm{~h}$
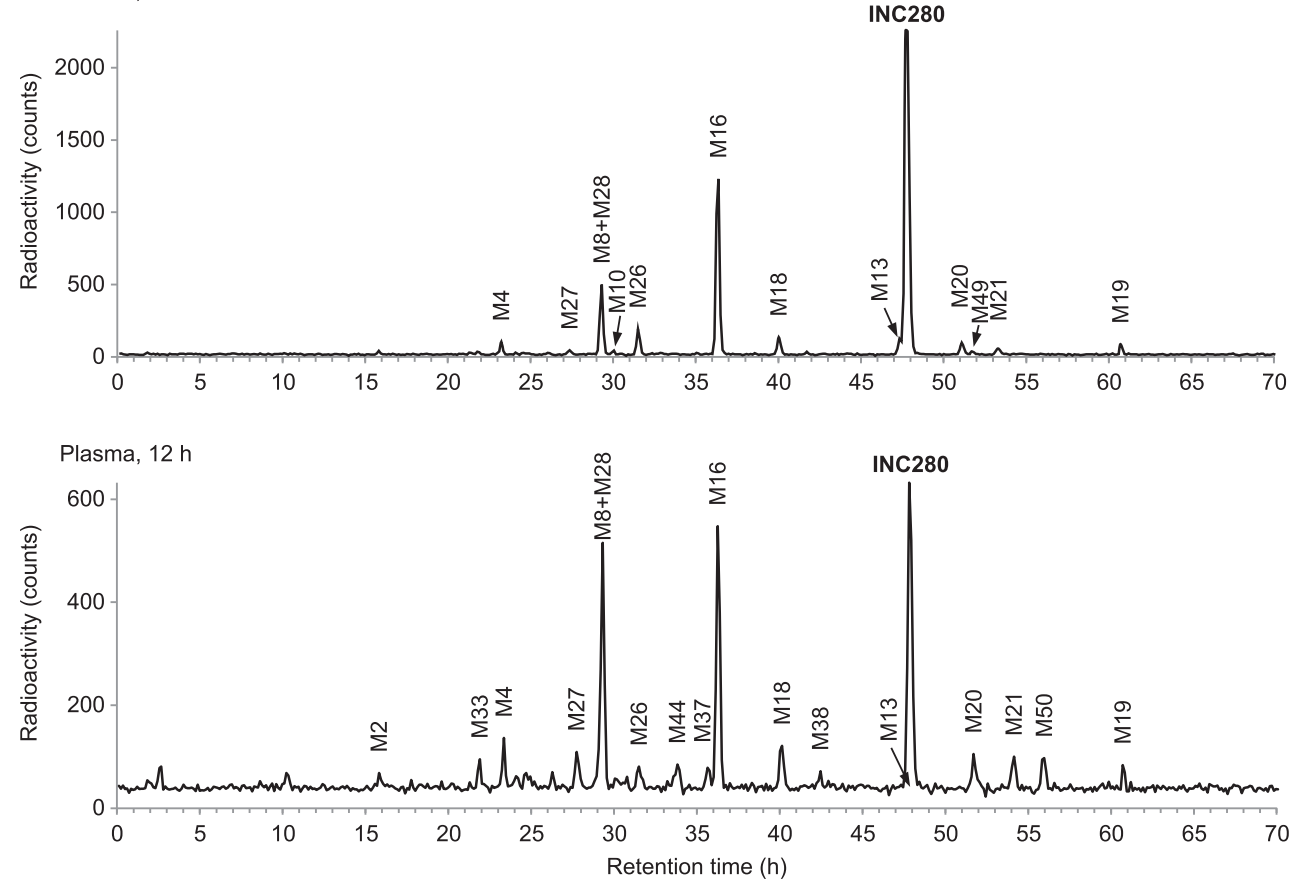

B Urine fraction pool 0-96 hours, analyzed by HPLC with detection of radioactivity in 96-well plates (Topcount ${ }^{\circledR}$ technique).

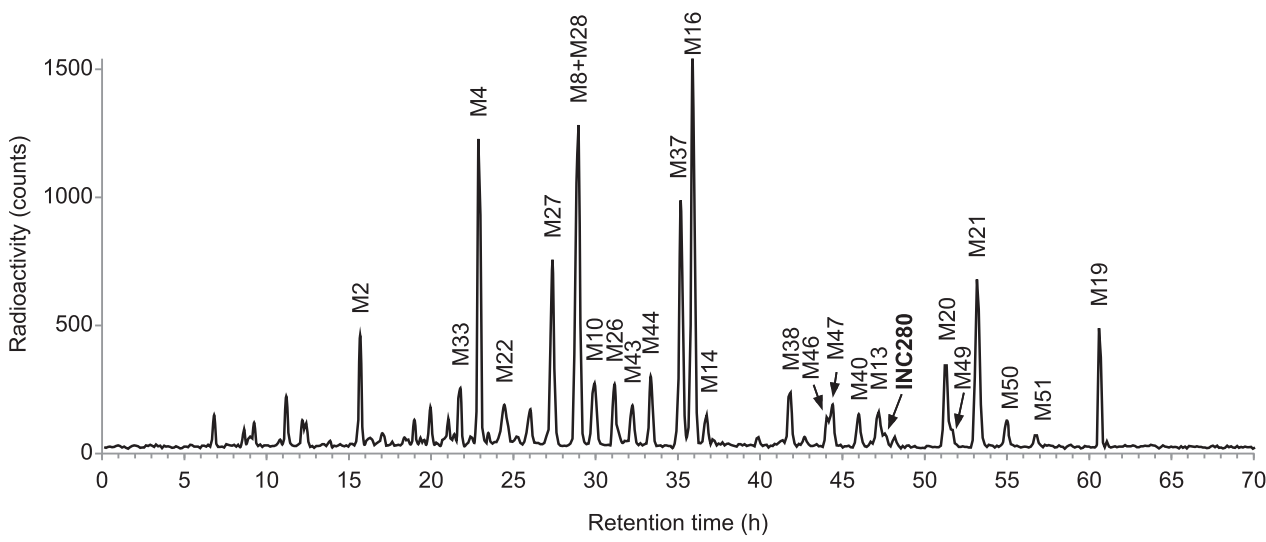

C Feces fraction pool 0-96 hours containing $97.9 \%$ of the total excreted dose in feces, analyzed by HPLC with detection of radioactivity in 96 -well plates (Topcount ${ }^{\circledR}$ technique).

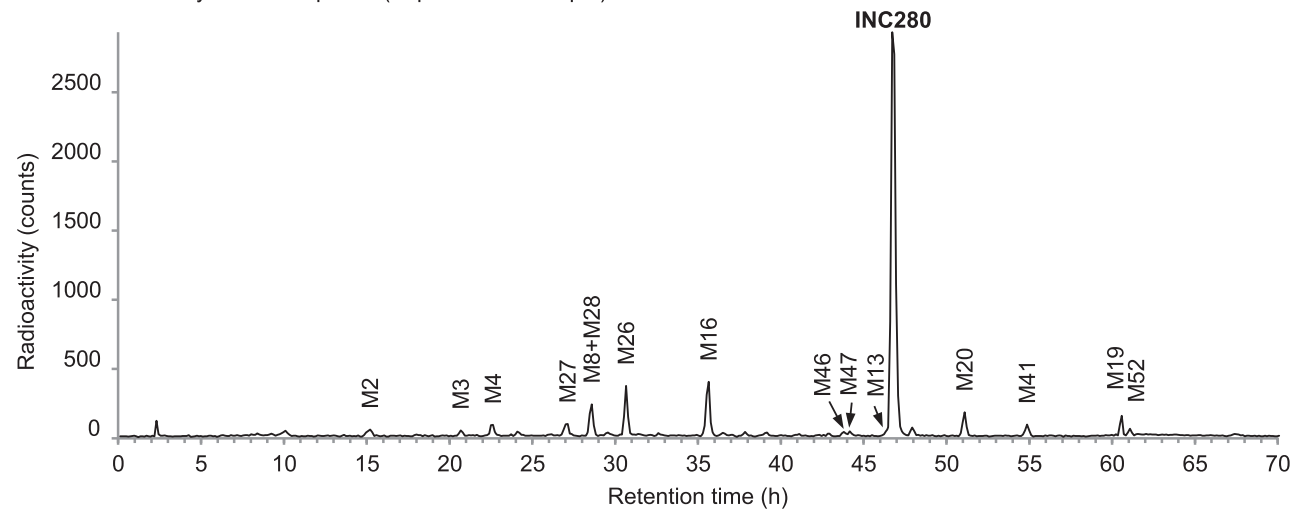

Fig. 4. (A) Representative metabolite profile in plasma at 2 and 12 hours. (B) Representative metabolite profiles in urine. (C) Representative metabolite profile in feces. (A) Representative plasma metabolite profile at $2\left(\mathrm{~T}_{\max }\right)$ and 12 hours obtained by HPLC after direct injection of a plasma extract and subsequent detection of radioactivity in 96-well plates (Topcount technique). (B) Urine fraction pool 0-96 hours, analyzed by HPLC with detection of radioactivity in 96-well plates (Topcount technique). (C) Feces fraction pool, 0-96 hours of containing $97.9 \%$ of the total excreted dose in feces, analyzed by HPLC with detection of radioactivity in 96-well plates (Topcount technique).

Retention time (h) 

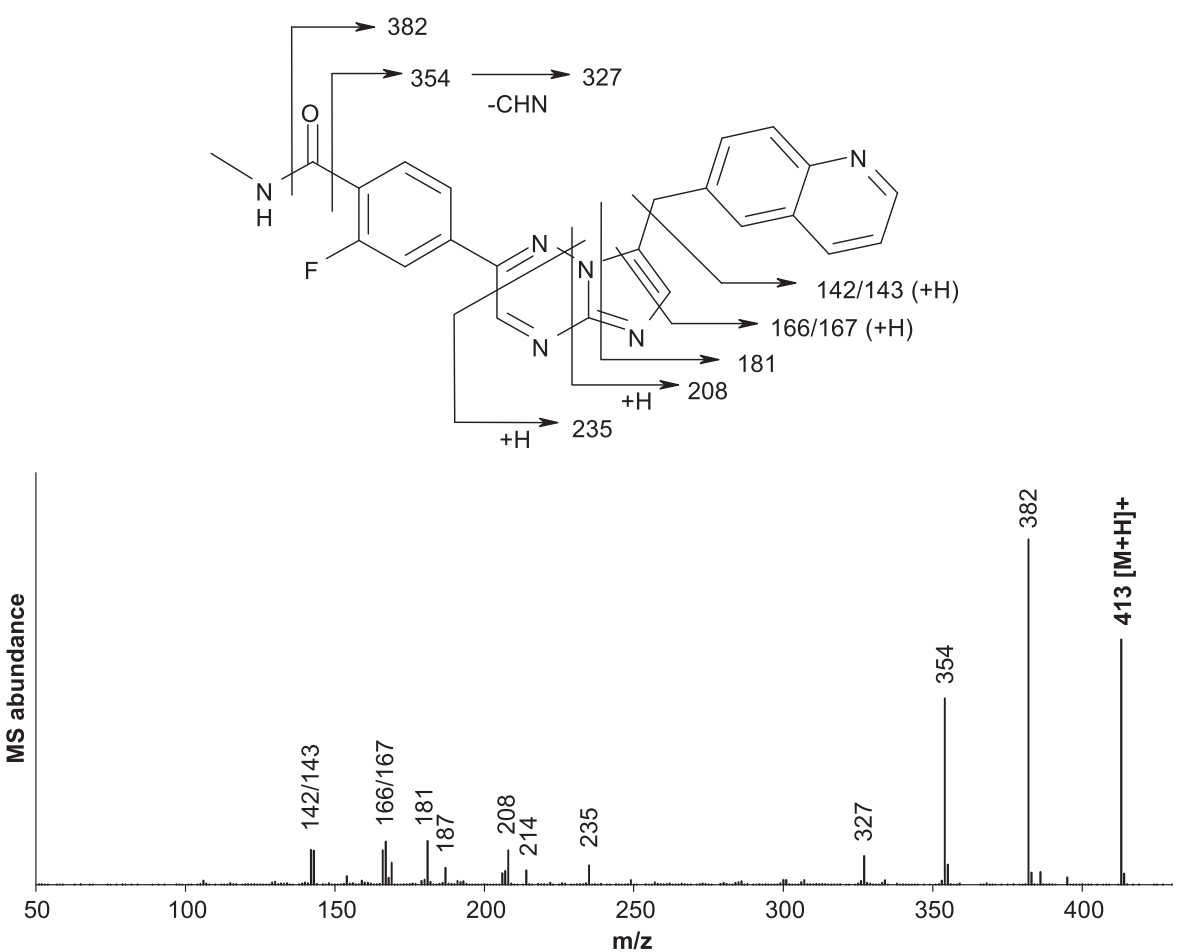

Fig. 5. Electrospray mass spectrum of capmatinib positive-ion mode, sample cone voltage $40 \mathrm{~V}$, trap collision energy ramp; 20-55 eV was used for electrospray ionization. The accurate mass measurements were in agreement with the proposed fragmentation. The differences between calculated and measured masses were $\leq 1.1 \mathrm{ppm}$ for all indicated fragment ions.
(Supplemental Table 2). A summary of incorporation of ${ }^{18} \mathrm{O}$ into the metabolites of $\left[{ }^{14} \mathrm{C}\right]$ capmatinib after incubation with human-relevant human-pooled primary hepatic coculture and cryopreserved human hepatocytes is provided in Supplemental Table 7. After incorporation of ${ }^{18} \mathrm{O}$ into the metabolite, a mass shift of two mass units of the $[\mathrm{M}+\mathrm{H}]^{+}$could be observed.

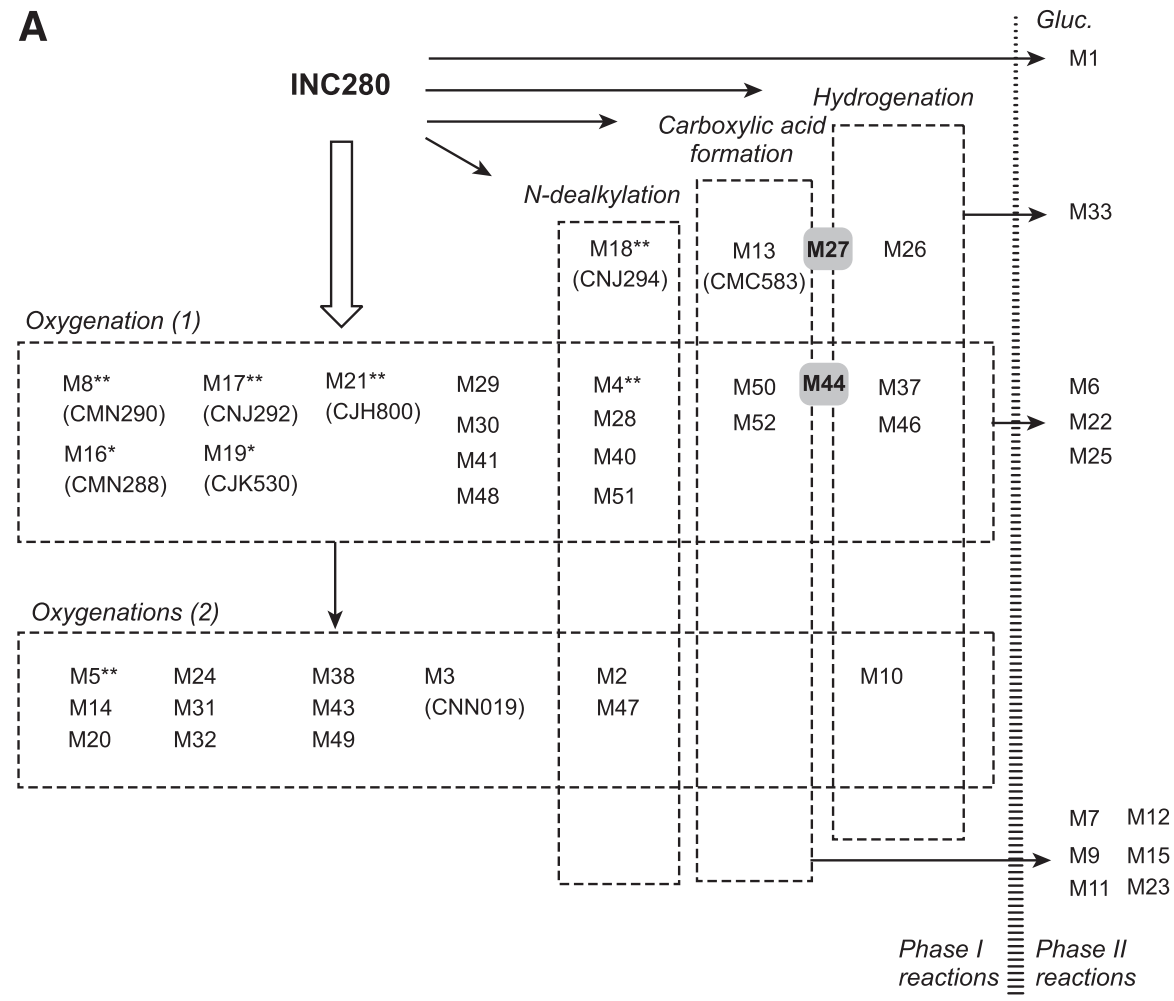

major metabolic pathway across all species except for dog

* involvement of AO and/or XO in human

** involvement of CYP enzymes in human
Fig. 6. (A) Proposed in vitro and in vivo biotransformation pathways of capmatinib in mouse, rat, dog, monkey, and/or human (schematic overview). (B) Scheme of biotransformation pathways in humans. 


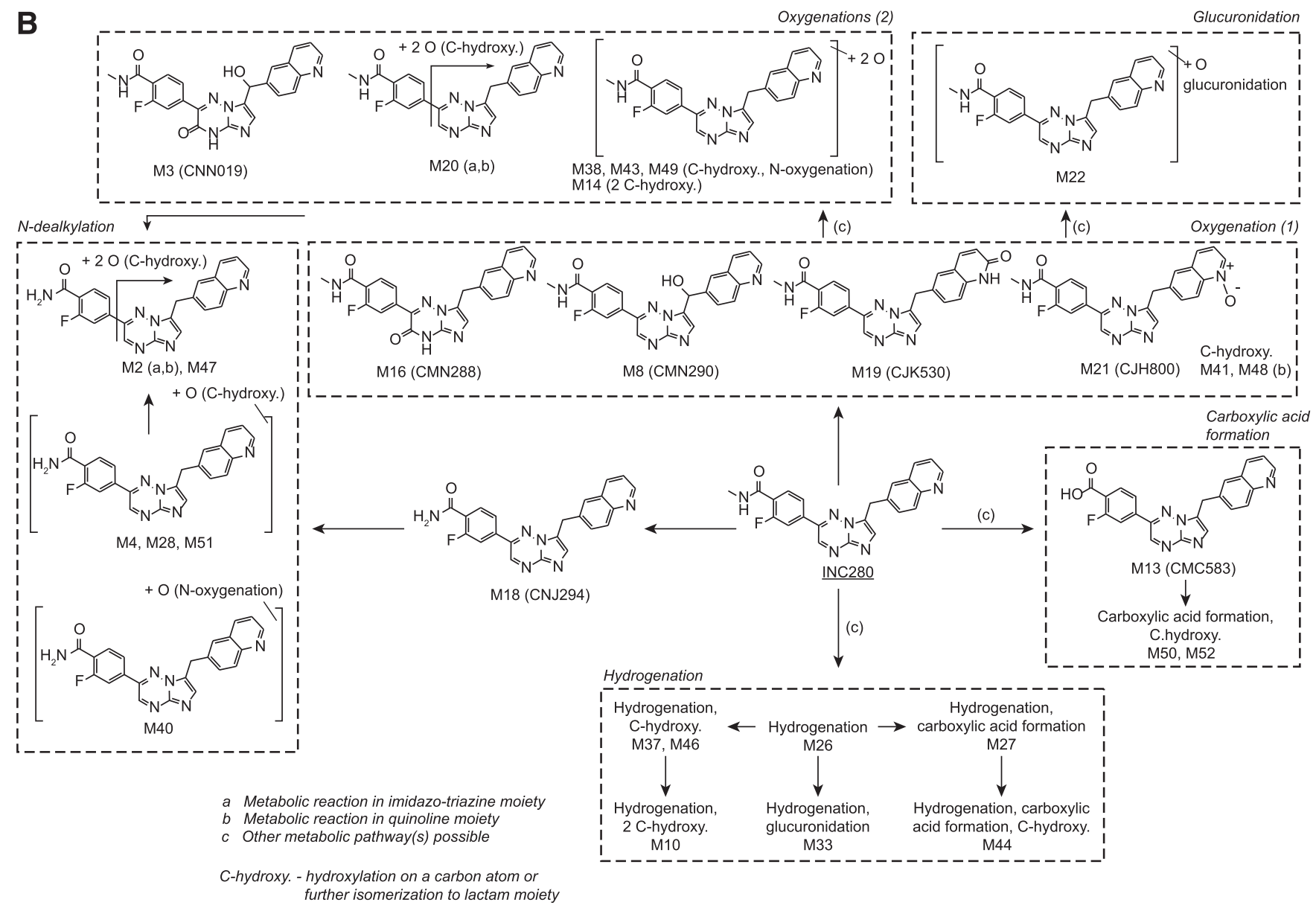

Fig. 6. Continued.

In vitro studies with capmatinib demonstrated that the metabolic behavior was consistent with that previously reported for AO substrates in that the $\mathrm{AO}$ metabolites are formed in rodents, nonhuman primates, and humans but not in dogs (Garattini and Terao, 2012); Supplemental Fig. 5; Supplemental Table 8).

In line with these observations, in vitro metabolic profiles obtained from incubations with ${ }^{14} \mathrm{C}$-capmatinib using mouse, rat, dog, monkey, and human hepatocytes were similar across species except for dog.

Identification of Human CYP P450 Enzymes Involved in the Oxidative Metabolism of Capmatinib in HLM. The biotransformation of capmatinib in HLM followed the Hill enzyme kinetics model and was characterized by a $K_{m}$ of $11.4 \mu \mathrm{M}$ and a $V_{\max }$ of 1969 $\mathrm{pmol} / \mathrm{min}$ per milligram (Supplemental Table 9). Kinetic constants for CYP1A2 $\left(\mathrm{K}_{\mathrm{m}}: 26.9 \pm 3.0 \mu \mathrm{M} ; \mathrm{V}_{\max }: 723 \pm 26 \mathrm{pmol} / \mathrm{min}\right.$ per nanomole, for sum of formation of M17 and M18), CYP2D6 $\left(\mathrm{K}_{\mathrm{m}}\right.$ : $13.0 \pm 3.0 \mu \mathrm{M} ; \mathrm{V}_{\max }: 902 \pm 56 \mathrm{pmol} / \mathrm{min}$ per nanomole, for sum of formation of M17, M18, and M21), and CYP3A4 ( $\mathrm{K}_{\mathrm{m}}: 3.30 \pm 0.44$ $\mu \mathrm{M} ; \mathrm{V}_{\text {max }}: 22,116 \pm 713 \mathrm{pmol} / \mathrm{min}$ per nanomole, for sum of formation of all metabolites) were determined. The derived intrinsic clearances $\left(\mathrm{V}_{\max } / \mathrm{K}_{\mathrm{m}}\right)$ of capmatinib were $26.9,69.4$, and $6702 \mu \mathrm{l} / \mathrm{nmol}$ per minute for CYP1A2, CYP2D6, and CYP3A4, respectively. In incubation experiments carried out with a panel of 18 recombinant CYPs and three recombinant flavin-containing monooxygenases, CYP1A1 and CYP3A4 showed the highest turnover under the experimental conditions used (Supplemental Fig. 6). Summary of CYP isoenzyme contributions to the total CYP-mediated oxidative metabolism in human liver microsomes based on recombinant CYP enzyme kinetics is provided in Supplemental Table 10. Strong inhibition was observed with ketoconazole and azamulin (CYP3A inhibitors, up to $80 \%$ and $92 \%$ inhibition, respectively). Other chemical inhibitors tested did not show significant inhibitory effects (Supplemental Fig. 7; Supplemental Table 11). Correlation analysis suggested that CYP3A is the major enzyme family involved in the hepatic microsomal metabolism of $\left[{ }^{14} \mathrm{C}\right]$ capmatinib (Supplemental Fig. 8; Supplemental Table 12).

\section{Safety Assessments}

There were no discontinuations, deaths, serious AEs, or other significant AEs during the study.

\section{Discussion}

Assuming that the drug is stable against intestinal bacterial enzymes, the mean oral absorption of capmatinib [based on urinary and fecal (as metabolites) excreted radioactivity, Supplemental Table 2] was estimated to be $49.6 \% \pm 20.9 \%$ and ranged between $21.0 \%$ and $81.7 \%$. The interindividual differences in exposure are likely caused by the difference in dissolution and differences in absorption. This is supported by the very similar patterns of relative metabolites in plasma, urine, and feces and the large absolute differences in total drug-related exposure in plasma and differences in total radioactivity excreted in feces and urine as well as large differences in capmatinib (likely not absorbed) in feces. Absorbed capmatinib was eliminated mainly because of metabolism and subsequent biliary/fecal and renal excretion. The study showed that the 
A $10 \mu \mathrm{M}\left[{ }^{14} \mathrm{C}\right]$ capmatinib was incubated with $0.3 \mathrm{mg} / \mathrm{mL}$ subcellular fractions for $30 \mathrm{~min}$ at $37^{\circ} \mathrm{C}$ in the presence or absence of NADPH
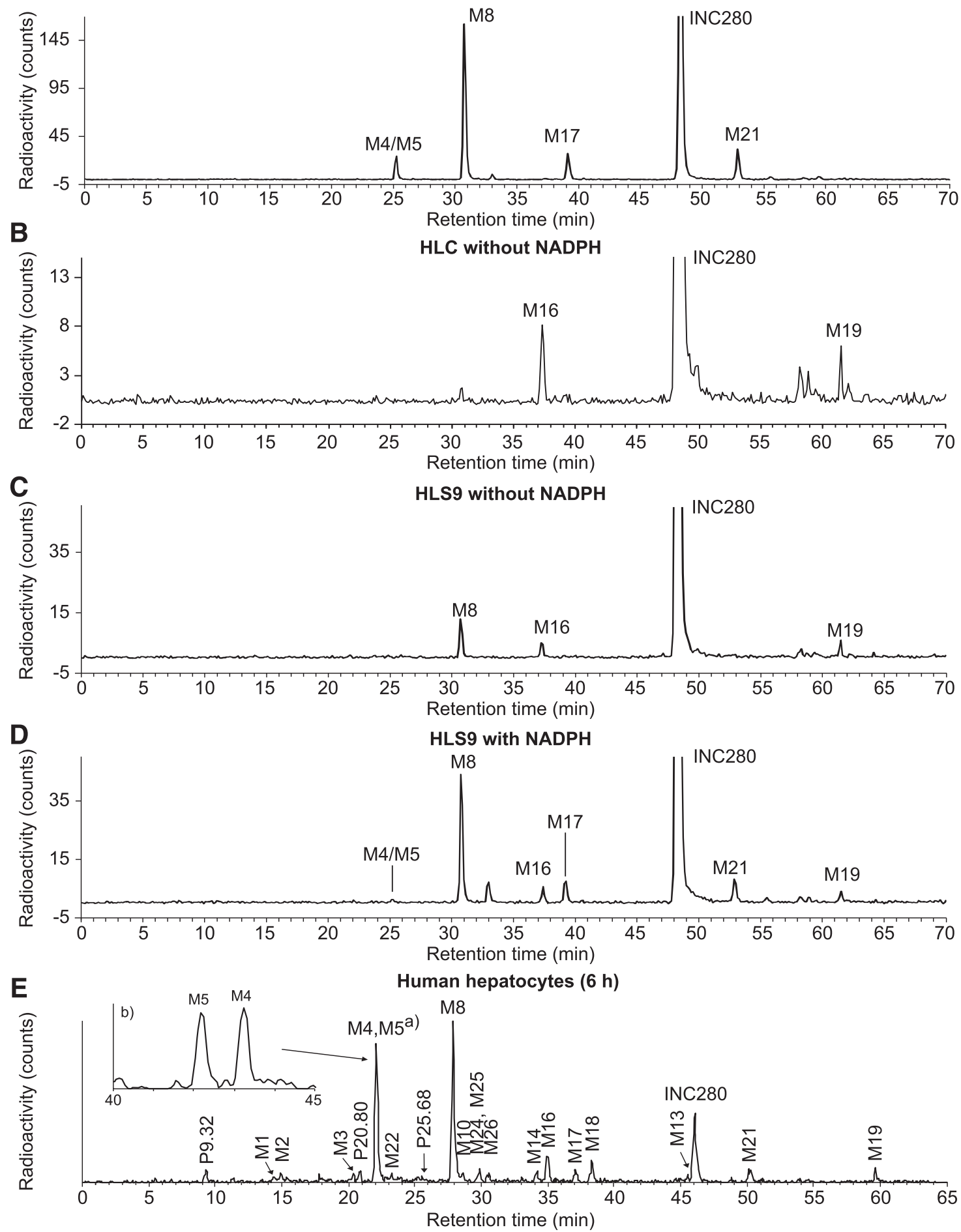

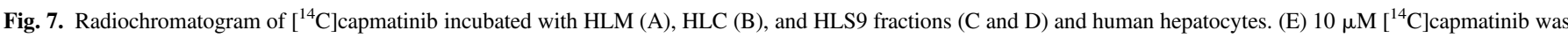

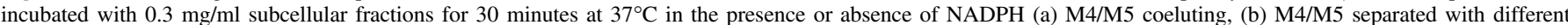
chromatographic method.

CL/F of capmatinib was moderate-to-high (30.0-121 1/h). Mean apparent elimination half-lives of total radiolabeled components (radioactivity) and capmatinib in plasma were 10.6 and 7.84 hours, respectively. The $\mathrm{Vz} / \mathrm{F}$ associated with the terminal phase calculated from plasma concentrations was 4731 . Thus, capmatinib was largely distributed to the peripheral tissues. The ratio of compound-related radioactivity between blood and plasma showed substantial variations but no special affinity of capmatinib and/or its metabolites for erythrocytes could be concluded. Metabolism mainly occurred by lactam formation, hydroxylation, N-dealkylation, formation of 


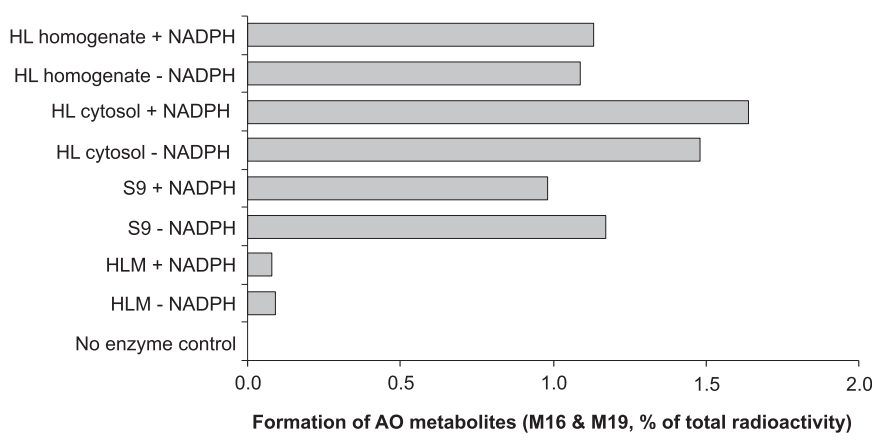

Fig. 8. Subcellular distribution and effect of cofactor NADPH on M16 + M19 formation in human liver subcellular fractions. HL, human liver.

a carboxylic acid, hydrogenation, N-oxygenation, glucuronidation, and combinations thereof. M16, the main circulating metabolite in humans, had been found in previous studies in the rat and in vitro investigations of metabolism. M16 was found to be the most abundant metabolite in both urine and feces and showed no measurable pharmacological activity.

In vitro enzyme-phenotyping studies were carried out to determine the enzymes involved in the catalysis of the formation of major hepatic metabolites. The presence of M16 and M19 in HLC and cytosol containing liver fractions and the catalysis of M16 and M19 formation even in absence of NADPH suggested that aldehyde oxidases (which were typically located in the cytosol) were involved in the metabolism of capmatinib and that HLC is the best hepatic cell fraction suitable for the phenotypic investigations of M16 and M19 formation.

$\mathrm{AO}$ is a cytosolic molybdenum-containing hydroxylase able to oxidize aldehydes and azaheterocyclic-containing molecules. It is known to catalyze the oxidation of N-heterocyclic drugs, such as famciclovir and zaleplon. Formation of an oxidative metabolite in an incubation with cytosolic or S9 fraction in the absence of NADPH reveals the contribution of a non-CYP450 enzyme in the oxidative metabolism. Consequently, the involvement of AO is confirmed by carrying out the same incubation in the presence of an $\mathrm{AO}$ inhibitor and observing a reduction in metabolite production (Pryde et al., 2010). AO is homologous with $\mathrm{XO}$, another mammalian molybdoflavoprotein. In general, AO has the ability to oxidize a broader range of substrates than XO (Kitamura et al., 2006).

The involvement of $\mathrm{AO}$ and $\mathrm{XO}$ in the metabolism of capmatinib and formation of metabolites M16 and M19 was demonstrated by the oxidation in the hepatic cytosol without the requirement of NADPH as a cofactor, metabolism by recombinant human $\mathrm{AO}$ and $\mathrm{XO}$, and chemical inhibition by enzyme-selective inhibitors of the two enzymes as well as oxygen incorporation into the primary metabolites M16 and M19 derived from water rather than molecular oxygen [molybdenum-containing hydroxylases $(\mathrm{AO} / \mathrm{XO})$ use water in their catalytic mechanism of oxidation rather than molecular oxygen] and also in combinations with other metabolic reactions for M2, M3, M28, M10, M14, M20, and M49. In sum, the metabolites M2, M3, M16, M19, M28, M10, M14, M20, and M49 formed by molybdenumcontaining hydroxylases partly in combination with other metabolic reactions represented $39.7 \% \pm 2.2 \%$ of the metabolites in the excreta of human. Hence, the contribution of $\mathrm{AO} / \mathrm{XO}$ to the metabolism of absorbed capmatinib is assumed to be $\leq 40 \%$.

Based on enzyme kinetic results with recombinant human CYPs, protein binding in microsomes, and the relative abundance of the currently known CYP P450 isoforms, it could be established that CYP3A was the major P450 enzyme involved in hepatic microsomal metabolism among all the known liver P450 enzymes. The metabolism of $\left[{ }^{14} \mathrm{C}\right]$ capmatinib in HLM was strongly inhibited by ketoconazole and azamulin (both CYP3A4/5 inhibitors). The results with selective inhibitors and recombinant enzymes are in agreement with data from the correlation analysis in HLM from individual donors. The strong activity of recombinant CYP1A1 suggests a possible involvement of this enzyme in the biotransformation of capmatinib in extrahepatic tissues.

\section{Conclusions}

After oral dosing of $600 \mathrm{mg}\left[{ }^{14} \mathrm{C}\right]$ capmatinib capsules in healthy male volunteers, rapid and substantial systemic availability to unchanged capmatinib was observed with moderate interindividual variability. Circulating metabolites were predominantly of oxidative nature with involvement of CYP3A4 and AO and a minor contribution by XO. The most abundant AO-derived metabolite in plasma (M16) has

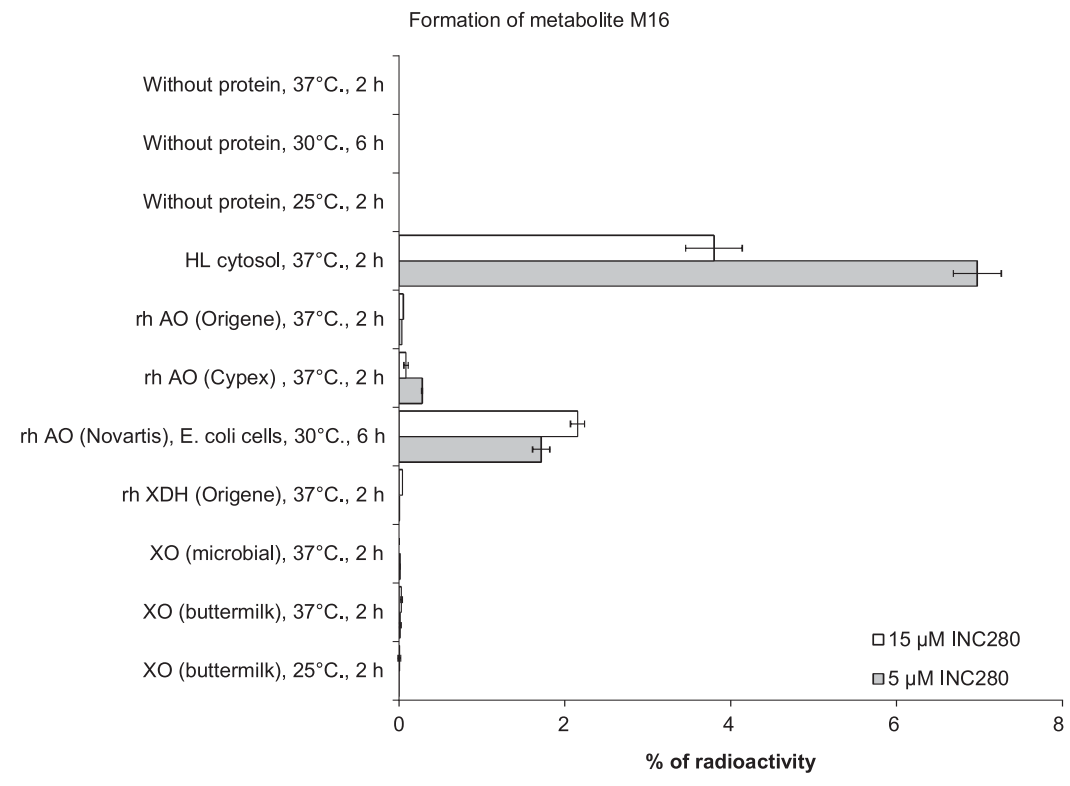

Fig. 9. Biotransformation of $\left[{ }^{14} \mathrm{C}\right]$ capmatinib to M16 by molybdenum hydroxylases. HL, human liver; rh, recombinant human; XDH, xanthine dehydrogenase. 

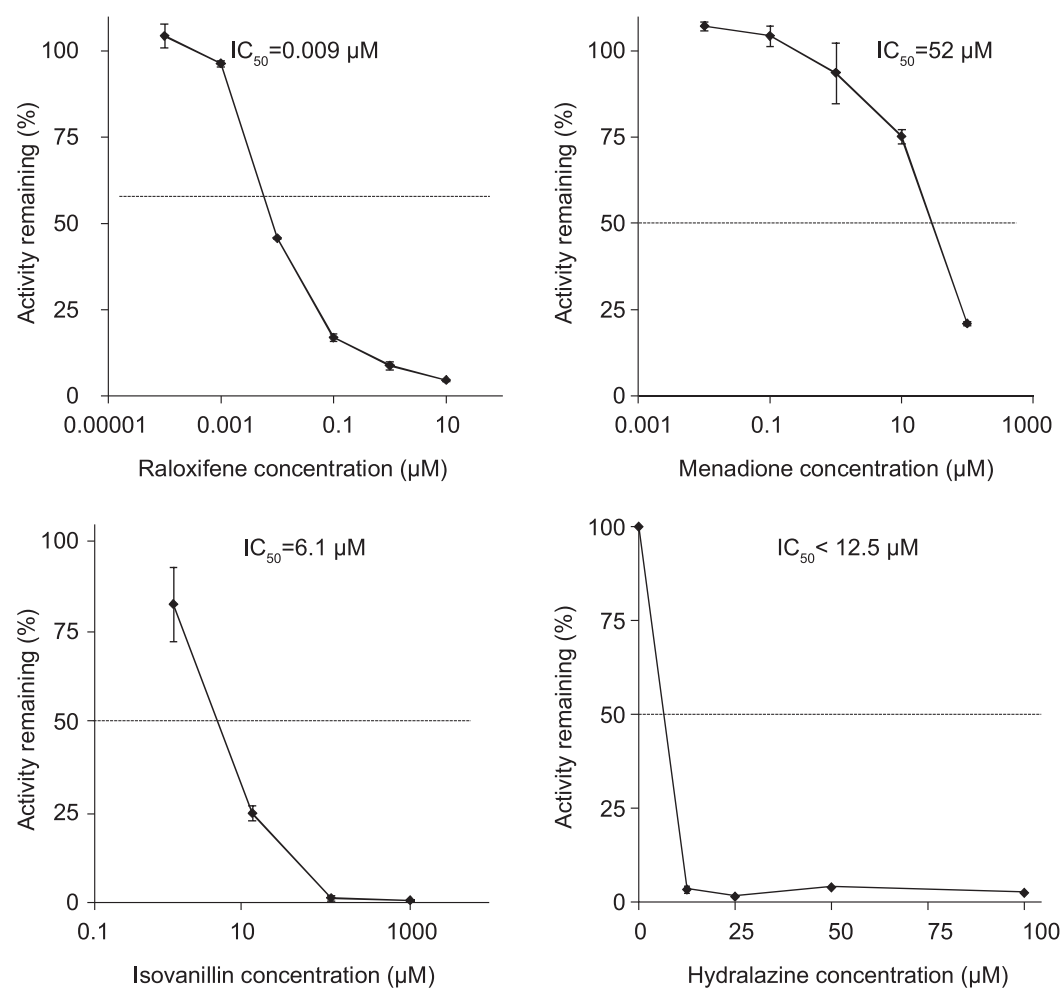

Fig. 10. Effect of chemical inhibitors on capmatinib metabolism in HLC (M16 formation)

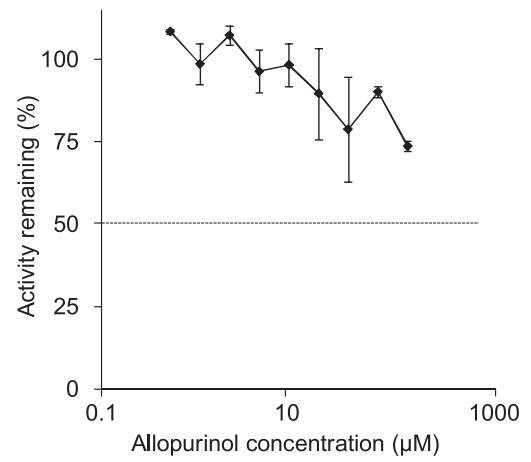

been identified in the rodent toxicity species (Wistar rat). Capmatinib demonstrated an apparent moderate-to-high volume of distribution and an apparent moderate-to-high clearance with extensive metabolic elimination. In vitro phenotyping investigations predict that inhibitors and/or inducers of AO and CYP3A4 could impact the hepatic metabolic clearance of capmatinib in humans. Elimination of absorbed capmatinib was mainly because of metabolism and subsequent biliary/fecal and renal excretion.

No safety concerns were identified in this study. A single 600-mg oral dose of $\left[{ }^{14} \mathrm{C}\right]$ capmatinib was safe and well-tolerated in healthy male volunteers.

\section{Acknowledgments}

We would like to thank the participants of this study from whom data were taken for analysis. We would also like to thank Albrecht Glänzel and Thomas Mönius (Isotope Laboratory, Novartis Pharma AG, Basel, Switzerland); Ulrich Onken and Leo Hardegger (Chemical and Analytical Development, Novartis Pharma AG, Basel, Switzerland) for the preparation of the radiolabeled drug or the synthesis of reference compounds; Robert Nufer and Claudia Sayer (Biotransformation Laboratory, Novartis Pharma AG, Basel, Switzerland); and Reinhard Zschoche and Mathieu Ligibel (Bioreactions Group, Novartis Pharma AG, Basel, Switzerland) for their excellent technical support. Medical editorial assistance was provided by Aarti Kamaraj (Novartis Healthcare Pvt. Ltd.).

\section{Authorship Contributions}

Participated in research design: Glaenzel, Jin, Hansen, Schroer, Pfaar, Borell, Camenisch, Zhao.

Conducted experiments: Glaenzel, Jin, Schroer, Jaap van Lier, Borell.

Contributed new reagents or analytic tools: Glaenzel, Jin, Schroer, Rahmanzadeh, Borell.

Performed data analysis: Glaenzel, Jin, Schroer, Pfaar, Borell, Meissner.

Wrote or contributed to the writing of the manuscript: Glaenzel, Jin, Hansen, Schroer, Rahmanzadeh, Pfaar, Jaap van Lier, Borell, Meissner, Camenisch, Zhao.

\section{References}

Awad MM, Oxnard GR, Jackman DM, Savukoski DO, Hall D, Shivdasani P, Heng JC, Dahlberg SE, Jänne PA, Verma S, et al. (2016) MET exon 14 mutations in non-small-cell lung cancer are associated with advanced age and stage-dependent MET genomic amplification and c-met overexpression. J Clin Oncol 34:721-730.

Baltschukat S, Engstler BS, Huang A, Hao HX, Tam A, Wang HQ, Liang J, DiMare MT, Bhang HC, Wang Y, et al. (2019) Capmatinib (INC280) is active against models of non-small cell lung cancer and other cancer types with defined mechanisms of MET activation. Clin Cancer Res 25: 3164-3175.

Cappuzzo F, Marchetti A, Skokan M, Rossi E, Gajapathy S, Felicioni L, Del Grammastro M, Sciarrotta MG, Buttitta F, Incarbone M, et al. (2009) Increased MET gene copy number 
negatively affects survival of surgically resected non-small-cell lung cancer patients. J Clin Oncol 27:1667-1674.

Descarpentries C, Leprêtre F, Escande F, Kherrouche Z, Figeac M, Sebda S, Baldacci S, Grégoire V, Jamme P, Copin M-C, et al. (2018) Optimization of routine testing for MET exon 14 splice site mutations in NSCLC patients. J Thorac Oncol 13:1873-1883.

Feng Y, Minca EC, Lanigan C, Liu A, Zhang W, Yin L, Pennell NA, Farver C, Tubbs R, and Ma PC (2014) High MET receptor expression but not gene amplification in ALK 2p23 rearrangement positive non-small-cell lung cancer. J Thorac Oncol 9:646-653.

Feng Y, Thiagarajan PS, and Ma PC (2012) MET signaling: novel targeted inhibition and its clinical development in lung cancer. $J$ Thorac Oncol 7:459-467.

Frampton GM, Ali SM, Rosenzweig M, Chmielecki J, Lu X, Bauer TM, Akimov M, Bufill JA, Lee C, Jentz D, et al. (2015) Activation of MET via diverse exon 14 splicing alterations occurs in multiple tumor types and confers clinical sensitivity to MET inhibitors. Cancer Discov 5: $850-859$.

Garajová I, Giovannetti E, Biasco G, and Peters GJ (2015) c-Met as a target for personalized therapy, Transl Oncogenomics 7 (Suppl 1):13-31.

Garattini Enrico and Terao Mineko (2012) The role of aldehyde oxidase in drug metabolism. Expert Opin Drug Metab Toxicol 8 (4):487-503, doi: 10.1517/17425255.2012.663352 22335465.

Kawakami H, Okamoto I, Okamoto W, Tanizaki J, Nakagawa K, and Nishio K (2014) Targeting MET amplification as a new oncogenic driver. Cancers (Basel) 6:1540-1552.

Kitamura S, Sugihara K, and Ohta S (2006) Drug-metabolizing ability of molybdenum hydroxylases. Drug Metab Pharmacokinet 21:83-98.

Kong-Beltran M, Seshagiri S, Zha J, Zhu W, Bhawe K, Mendoza N, Holcomb T, Pujara K, Stinson J, Fu L, et al. (2006) Somatic mutations lead to an oncogenic deletion of met in lung cancer Cancer Res 66:283-289.

Lara MS, Holland WS, Chinn D, Burich RA, Lara PN Jr., Gandara DR, Kelly K, and Mack PC (2017) Preclinical evaluation of MET inhibitor INC-280 with or without the epidermal growth factor receptor inhibitor erlotinib in non-small-cell lung cancer. Clin Lung Cancer 18:281-285.

Liu X, Wang Q, Yang G, Marando C, Koblish HK, Hall LM, Fridman JS, Behshad E, Wynn R, Li Y, et al. (2011) A novel kinase inhibitor, INCB28060, blocks c-MET-dependent signaling, neoplastic activities, and cross-talk with EGFR and HER-3. Clin Cancer Res 17:7127-7138.

Ludovini V, Bianconi F, Pistola L, Pistola V, Chiari R, Colella R, Bellezza G, Tofanetti FR, Siggillino A. Baldelli E, et al. (2012) Optimization of patient selection for EGFR-TKIs in advanced non-small cell lung cancer by combined analysis of KRAS, PIK3CA, MET, and nonsensitizing EGFR mutations. Cancer Chemother Pharmacol 69:1289-1299.

Ma B, Bang YJ, Lim WT, Nam DH, Su WC, Schellens JHM, Azaro A, Akimov M, Zhang Y, Kumar A, et al. (2015) Phase I dose escalation and expansion study to evaluate safety and efficacy of INC280 in patients with advanced MET-dependent solid tumors. Ann Oncol 26:ii16.

Pryde DC, Dalvie D, Hu Q, Jones P, Obach RS, and Tran TD (2010) Aldehyde oxidase: an enzyme of emerging importance in drug discovery. J Med Chem 53:8441-8460.

Salgia R (2017) MET in lung cancer: biomarker selection based on scientific rationale. Mol Cancer Ther 16:555-565.
Schildhaus HU, Schultheis AM, Ruschoff J, Binot E, Merkelbach-Bruse S, Fassunke J, Schulte W, Ko YD, Schlesinger A, Bos M, et al. (2015) MET amplification status in therapy-naive adenoand squamous cell carcinomas of the lung. Clin Cancer Res 21:907-915.

Schrock AB, Frampton GM, Suh J, Chalmers ZR, Rosenzweig M, Erlich RL, Halmos B, Goldman J, Forde P, Leuenberger K, et al. (2016) Characterization of 298 patients with lung cancer harboring MET exon 14 skipping alterations. J Thorac Oncol 11:1493-1502.

Schuler M, Berardi R, Lim WT, de Jonge M, Bauer TM, Azaro A, Gottfried M, Han JY, Lee DH, Hong D, et al. (2018) Phase I dose expansion results from a multicenter, open-label study of the MET inhibitor capmatinib (INC280) in adult patients with MET-dysregulated advanced NSCLC Poster Abstracts. European Journal of Cancer 103:e23-e147. https://reader.elsevier.com/reader/ sd/pii/S0959804918314916?token=0CBFD5AEA7D6E7A980C6DA76F91B2788DF660DEA0 E9F1CE87A48EC9A1A60A00CDEB5B5CBA80A2D5A7FFA7C4C8218868A0014-2964

Sierra JR and Tsao M-S (2011) c-MET as a potential therapeutic target and biomarker in cancer. Ther Adv Med Oncol 3 (Suppl):S21-S35.

Smyth EC, Sclafani F, and Cunningham D (2014) Emerging molecular targets in oncology: clinical potential of MET/hepatocyte growth-factor inhibitors. OncoTargets Ther 7:1001-1014.

The Cancer Genome Atlas Research Network (2014) Comprehensive molecular profiling of lung adenocarcinoma [published correction appears in Nature (2014) 514:262]. Nature 511:543.

Tong JH, Yeung SF, Chan AW, Chung LY, Chau SL, Lung RW, Tong CY, Chow C, Tin EK, Yu $\mathrm{YH}$, et al. (2016) MET amplification and exon 14 splice site mutation define unique molecular subgroups of non-small cell lung carcinoma with poor prognosis. Clin Cancer Res 22: 3048-3056.

Vuong HG, Ho ATN, Altibi AMA, Nakazawa T, Katoh R, and Kondo T (2018) Clinicopathological implications of MET exon 14 mutations in non-small cell lung cancer - a systematic review and meta-analysis. Lung Cancer 123:76-82.

Wolf J, Seto T, Han J-Y, Reguart N, Garon EB, Groen HJM, Tan DS-W, Hida T, De Jonge MJ, Orlov SV, et al. (2019) Capmatinib (INC280) in MET $\Delta$ ex14-mutated advanced non-small cell lung cancer (NSCLC): efficacy data from the phase II GEOMETRY mono-1 study. 37:9004.

Wu Y-L, Zhang L, Kim D-W, Liu X, Lee DH, Yang JC-H, Ahn M-J, Vansteenkiste JF, Su W-C Felip E, et al. (2018) Phase ib/II study of capmatinib (INC280) plus gefitinib after failure of Epidermal Growth Factor Receptor (EGFR) inhibitor therapy in patients with EGFR-mutated, MET factor-dysregulated non-small-cell lung cancer. J Clin Oncol 36:3101-3109.

Zou HY, Li Q, Lee JH, Arango ME, McDonnell SR, Yamazaki S, Koudriakova TB, Alton G, Cui JJ, Kung PP, et al. (2007) An orally available small-molecule inhibitor of c-Met, PF-2341066, exhibits cytoreductive antitumor efficacy through antiproliferative and antiangiogenic mechanisms. Cancer Res 67:4408-4417.

Address correspondence to: PK-Sciences, Novartis Pharma AG, Fabrikstrasse 14, WSJ-1531.02 Basel 4056, Switzerland. E-mail: ulrike.glaenzel@novartis.com 